\title{
Age-dependent HLA Genetic Heterogeneity of Type 1 Insulin-dependent Diabetes Mellitus
}

\author{
Sophie Caillat-Zucman, * Henri-Jean Garchon, * José Timsit, * Roger Assan, ${ }^{\star}$ Christian Boitard, * \\ Idriss Djilali-Saiah, ** Pierre Bougnères, ${ }^{*}$ and Jean-François Bach* \\ *Institut National de la Sante et de la Recherche Medicale U 25, Hôpital Necker; ${ }^{\ddagger}$ Service d’Endocrinologie, Hôpital Bichat; \\ and ${ }^{\S}$ Service d'Endocrinologie Pediatrique, Hôpital Saint-Vincent de Paul, Paris, France
}

\begin{abstract}
The association of insulin-dependent diabetes mellitus (IDDM) with certain HLA alleles is well documented in pediatric patients. Whether a similar association is found in adult-onset IDDM is not clear, although the disease occurs after the age of 20 in $50 \%$ of cases. HLA class II DRB1, DQA1, and DQB1 alleles were studied in 402 type I diabetics and 405 healthy controls (all Caucasian) using oligonucleotide typing after gene amplification. Alleles DRB1 *03, DRB1 *04, DQB1 *0201, DQB1 *0302, DQA1 *0301, and DQA1*0501 were indeed enriched in diabetics and the highest relative risk was observed in patients carrying both the DRB1 *03-DQB1 *0201 and the DRB1 *0402 or DRB1 *0405-DQB1 *0302 haplotypes. However none of these alleles, or specific residues, could alone account for the susceptibility to IDDM. Furthermore, there were major differences in HLA class II gene profiles according to the age of onset. Patients with onset after $15 \mathrm{yr}(n=290)$ showed a significantly higher percentage of non-DR3/non-DR4 genotypes than those with childhood onset $(n=112)$ and a lower percentage of DR3 / 4 genotypes. These non-DR3 / non-DR4 patients, although presenting clinically as IDDM type 1 patients, showed a lower frequency of islet cell antibodies at diagnosis and a significantly milder initial insulin deficiency. These subjects probably represent a particular subset of IDDM patients in whom frequency increases with age. The data confirm the genetic heterogeneity of IDDM and call for caution in extrapolating to adult patients the genetic concepts derived from childhood IDDM. (J. Clin. Invest. 1992. 90:2242-2250.) Key words: type 1 insulin-dependent diabetes mellitus genetics • adult-onset insulin-dependent diabetes mellitus • oligotyping • polymerase chain reaction $\cdot$ HLA class II genes
\end{abstract}

\section{Introduction}

Convergent arguments indicate that insulin-dependent diabetes mellitus (IDDM) ${ }^{1}$ is secondary to the autoimmune de-

Address correspondence to Sophie Caillat-Zucman, M.D., INSERM U 25, Hôpital Necker, 161 rue de Sevres, 75015 Paris, France.

Received for publication 2 October 1991 and in revised form 22 June 1992.

1. Abbreviations used in this paper: $\mathrm{Cs}-\mathrm{A}$, cyclosporin $\mathrm{A}$; $\mathrm{HbA1C}$, glycosylated hemoglobin; IAA, insulin autoantibodies; ICA, islet cell antibodies; IDDM, insulin-dependent diabetes mellitus; NIDDM, non-insulin-dependent diabetes mellitus; PCR, polymerase chain reaction; $\mathrm{RR}$, relative risk; SSO, sequence-specific oligonucleotides; TMAC, tetramethylammonium chloride.

J. Clin. Invest.

(c) The American Society for Clinical Investigation, Inc.

$0021-9738 / 92 / 12 / 2242 / 09 \quad \$ 2.00$

Volume 90, December 1992, 2242-2250 struction of $\beta$ cells in the pancreatic islets of Langerhans (1). IDDM has long been known to be associated with particular HLA alleles and there is substantial evidence from family studies that the major loci that confer disease susceptibility map to the class II region of the MHC (2). Among Caucasians, the disease is positively associated with DR3 and DR4 and negatively associated with DR2 (3-5). Recently, on the basis of restriction length fragment polymorphism (RFLP) and oligonucleotide typing, the notion has emerged that IDDM susceptibility or resistance is preferentially associated with a limited number of alleles of the HLA-DQB locus (6-10). Susceptibility has also been assigned to $\mathrm{DQB} 1$ alleles encoding amino acids other than aspartic acid (Asp) at position 57 of the DQ $\beta$ chain (11-14). However, an exclusive role of DQB genes (particularly the Asp 57 residue) is unlikely given the growing evidence that a single allele cannot account for MHC-associated genetic susceptibility. To take account of a possible genetic heterogeneity, accurate assessment of the HLA-IDDM association should involve extensive definition of class II alleles and integrate this with clinical and immunological parameters in a large series of patients. In most studies, a limited number of alleles has been tested and patients have not been investigated beyond the diagnosis of IDDM. Furthermore, most reported data have been obtained in pediatric patients, although IDDM occurs over the age of $20 \mathrm{yr}$ in one half of cases (15).

Class II oligotyping is a rapid and efficient tool that can be used for large-scale screening (16). It permits exquisite definition of HLA polymorphism and provides an important means of recognizing genes associated with disease susceptibility or resistance. Taking advantage of our access to large groups of adult- and childhood-onset IDDM patients with well-defined clinical, biological, and immunological status, we assessed the role of class II alleles in IDDM predisposition and presentation. Using DNA amplification followed by hybridization with sequence-specific oligonucleotides (SSO), we studied 290 adultonset IDDM patients, 112 diabetic children, and 405 healthy controls for 24 DRB1, 8 DQA1, and 12 DQB1 alleles. An attempt was made to correlate HLA genotype with various clinical and immunological characteristics, notably the age at onset of IDDM.

This analysis provided five main results: $(a)$ Maximal susceptibility was defined by alleles at both DRB1 and DQB1 loci, since neither of these loci can alone account for the entire risk. (b) The specific contribution of DQAl could not be clearly defined. $(c)$ The highest risk for developing IDDM was found in individuals carrying the DR3 haplotype together with the DRB $1{ }^{*} 0402$ or DRB $1{ }^{*} 0405-D Q B 1{ }^{*} 0302$ haplotype, indicating the existence of $c i s$ - and/or trans-interacting elements in subjects with DR4 haplotypes. (d) Significant genetic heterogeneity was observed, with a lower frequency of DR3/DR4 heterozygotes and of non-Asp DQ $\beta 57$ residues, as well as a higher frequency of non-DR3/non-DR4 subjects in adult-onset 
IDDM compared with childhood-onset IDDM. (e) No clear correlation was found between HLA genotype and clinical or immunological features in a subgroup of 190 adult-onset IDDM patients particularly analyzed for various criteria, except for the rarity of islet cell antibodies in non-DR3/non-DR4 patients.

\section{Methods}

Subjects. 405 unrelated Caucasian patients were studied. Diabetes mellitus was defined using the National Diabetes Data Group recommendations (17). Concerning the classification criteria, the definition of insulin dependency is essentially phenotypic, whereas genetic studies require strict nosologic criteria. Type 1 IDDM is easy to recognize when it occurs in children, adolescents, and adults younger than $30 \mathrm{yr}$. Beyond this age, a stringent set of criteria is necessary, to exclude the misleading cases of "maturity-onset diabetes in the young" among the younger patients and of pancreatic diabetes or type 2 IDDM among older patients. Not only abrupt onset of symptoms, insulinopenia, proneness to ketosis, and dependence on injected insulin to sustain life (17) are required, but also absence of pancreatic diabetes and of clinical history of type 2 diabetes with secondary failure of oral antidiabetic drugs.

Among the IDDM patients, 112 were children $<15$ yr old. Sex ratio (males/females) was 47:65. Their mean age at onset was 11.0 $04 \mathrm{yr}$ $($ mean \pm SD). Duration of symptoms at diagnosis was $9.2 \pm 1.2 \mathrm{wk}$, and percentage of weight loss was $8.1 \pm 0.7$. Ketosis and ketoacidosis at diagnosis were found in 84 and $46.5 \%$ of cases, respectively. The initial glycosylated hemoglobin ( $\mathrm{HbAlC}$ ) was $12.4 \pm 0.3 \%$ (normal: $5.0 \pm 0.05 \%$ ). Insulin requirement during the first weeks of treatment was $0.60 \pm 0.1 \mathrm{U} / \mathrm{kg}$ per $\mathrm{d}$. The prevalence of islet cell antibodies (ICA) at onset was $69 \%$ and of insulin autoantibodies (IAA) was $25 \%$. Extrapancreatic autoimmune disease was never present.

The adult group consisted of 290 patients. Age distribution was $15-20 \mathrm{yr}$ in $77,20-30 \mathrm{yr}$ in 106, and $>30 \mathrm{yr}$ in 107 (mean age at diagnosis $27 \pm 7 \mathrm{yr}$ ). There were 154 males and 136 females. The clinical duration of the disease was $<6$ mo in all cases, with a mean of $7.6 \pm 6.8 \mathrm{wk}($ mean $\pm \mathrm{SD})$. Ketosis and ketoacidosis had revealed the diabetes in 62 and $19 \%$ of the cases, respectively. A family history of type 1 diabetes was present in a mean of $21 \%$ and an extrapancreatic autoimmune disease was present in $18.2 \% .190$ of these adult subjects were included in a cyclosporin A (Cs-A) therapeutic trial $(18,19)$, were analyzed in particular detail, and can be considered representative of the whole adult group ( Table I). Their mean age was $26 \pm 9 \mathrm{yr}$, with an age distribution similar to that of the whole adult group: 58 were 15-20 $\mathrm{yr}, 74$ were $20-30 \mathrm{yr}$, and 58 were $>30 \mathrm{yr}$. The mean duration of the disease was $7.2 \pm 6.7 \mathrm{wk}$. Ketosis and ketoacidosis were found in 57 and $12.5 \%$ of the cases, respectively, at diagnosis. The initial HbAlC was $11.5 \pm 0.2 \%$. The body mass index $\left(22.1 \pm 2.9 \mathrm{~kg} / \mathrm{cm}^{2}\right)$ was at the low end of the normal range and rapid and significant weight loss had been observed in most cases. A family history of diabetes was present in a mean of $25 \%$ and an extrapancreatic autoimmune disease was present in $8.2 \%$. Insulin requirements during the first few weeks of treatment were $0.70 \pm 0.03 \mathrm{U} / \mathrm{kg}$ per d. ICA were found at onset in 57 to $68 \%$ of cases by means of conventional (20) and sensitized (21) methods and IAA were found before insulin treatment in $24.8 \%$.

A glucagon test was performed within $15 \mathrm{~d}$ of diagnosis to evaluate residual insulin secretion. Blood glucose and plasma $C$ peptide concentrations were measured in blood samples obtained before, and 5, 10, and $15 \mathrm{~min}$ after the intravenous injection of $1 \mathrm{mg}$ of glucagon. Basal plasma $\mathrm{C}$ peptide levels were significantly lower than in 23 healthy controls $(0.71 \pm 0.04$ vs. $2.40 \pm 0.30 \mathrm{ng} / \mathrm{ml})$. The maximal secretory response after glucagon stimulation was $1.04 \pm 0.08$ versus $5.30 \pm 0.30 \mathrm{ng} /$ $\mathrm{ml}$ in the healthy controls. The intravenous glucose tolerance test ( $30 \mathrm{~g}$ i.v.) and standard meal test gave similar results (data not shown). All tests were performed in patients with stable metabolic conditions; in particular, hyper- or hypoglycemia was not recorded in the $12 \mathrm{~h}$ preced-
Table I. Clinical, Biochemical, and Autoimmune Characteristics of the Childhood-and Adult-onset IDDM Patient Groups

\begin{tabular}{lccc}
\hline & \multicolumn{2}{c}{ Adult onset } & \\
\cline { 2 - 3 } & All & Cs-A treated & $\begin{array}{c}\text { Childhood } \\
\text { onset }\end{array}$ \\
\hline Number of patients & 290 & 190 & 112 \\
Age at diagnosis (yr) & $26.7 \pm 7.5$ & $26.1 \pm 8.6$ & $11.0 \pm 0.4$ \\
Duration of symptoms (wk) & $7.6 \pm 6.8$ & $7.2 \pm 6.7$ & $9.2 \pm 1$ \\
Percent of weight loss & - & $9.0 \pm 5.8$ & $8.1 \pm 0.7$ \\
Family history of IDDM (\%) & 20.7 & 23.2 & - \\
Family history of NIDDM (\%) & 25.9 & 26.6 & - \\
Associated autoimmune & & & \\
$\quad$ diseases (\%) & 18.2 & 8.4 & 0 \\
Ketosis (\% of patients) & 61.7 & 56.8 & 84 \\
Ketoacidosis (\% of patients) & 19.1 & 12.5 & 46.5 \\
HbAlC (\%) & - & $11.5 \pm 0.2$ & $12.4 \pm 0.3$ \\
ICA (\% of patients) & - & 57.5 & 69 \\
IAA $\geq 2 \%$ insulin binding & & & \\
$\quad$ (\% of patients) & - & 32.1 & 25 \\
\hline
\end{tabular}

Results are presented as mean $\pm \mathrm{SD}$.

—, data are not available for this patient group.

ing the test. The tests were repeated every $3 \mathrm{mo}$ for $24 \mathrm{mo}$ and showed significant increases over initial values, which were more pronounced in the Cs-A-treated patients; all C peptide values remained lower than in controls, as reported in detail elsewhere (22). Pancreatic diabetes, i.e., pancreatitis and hemochromatosis, was excluded in every case. No patient had a clinical history of non-insulin-dependent diabetes mellitus (NIDDM) with secondary failure of oral antidiabetic drugs requiring insulin therapy. All subjects required insulin to maintain glycemic control, including (after a few months or years) those who had participated in the Cs-A therapeutic trial.

Since all newly diagnosed diabetic patients are hospitalized for initiation of insulin therapy and education, hospital-based selection can be excluded. The control population consisted of 405 healthy Caucasian individuals randomly selected among volunteer blood donors. Blood donor samples were collected from blood centers in six regions of France and the diabetic patients were recruited throughout the country. Both groups were representative of the mixed Caucasian French population in Paris and other areas of France.

DNA extraction and polymerase chain reaction (PCR). DNA was extracted from $2 \mathrm{ml}$ of fresh whole blood using short proteinase $\mathrm{K}$ digestion of detergent-treated cells (23). The second exons encoding the polymorphic outer domains of the HLA DR $\beta 1, \mathrm{DQ} \alpha 1$, and DQ $\beta 1$ chains were separately amplified following the PCR procedure, using specific DNA flanking primers $(24,25)$. Amplification was carried out for 30 cycles by adding $1.25 \mathrm{U}$ of Taq polymerase (Beckman Instruments, Fullerton, CA ), 25 pmol of each primer, and $200 \mu \mathrm{M}$ dNTP to 1 $\mu \mathrm{g}$ of genomic DNA. The size of amplified products was determined by means of agarose gel electrophoresis.

Dot blot and oligonucleotide hybridization. Amplified DNA was blotted onto nylon membranes using a robotic workstation (Biomek 1000; Beckman Instruments). Filters were denaturated for $10 \mathrm{~min}$ in $0.4 \mathrm{~N} \mathrm{NaOH}$ and baked for $1 \mathrm{~h}$ at $80^{\circ} \mathrm{C}$. Membranes were prehybridized for $30 \mathrm{~min}$ at $54^{\circ} \mathrm{C}$ in tetramethylammonium chloride (TMAC) solution ( 50 mM Tris-HCl pH 8.0, 2 mM EDTA, $5 \times$ Denhardt's, $0.1 \%$ SDS, and 3.0 M TMAC). Hybridization was performed overnight in TMAC solution with digoxigenin-11-dd UTP-labeled SSOs. Filters were washed twice in $2 \times$ SSPE $0.1 \%$ SDS at room temperature for 5 min, and then twice in TMAC solution ( $50 \mathrm{mM}$ Tris- $\mathrm{HCl} \mathrm{pH} 8.0,2$ $\mathrm{mM}$ EDTA, $0.1 \% \mathrm{SDS}$, and $3.0 \mathrm{M}$ TMAC) at $59^{\circ} \mathrm{C}$ for $10 \mathrm{~min}$. 
A chemoluminescence substrate (AMPPD) was used for detection according to the manufacturer's recommendations (Boehringer Mannheim Biochemicals, Indianapolis, IN). Filters were exposed to Kodak XAR-5 films at room temperature for 1 to $15 \mathrm{~min}$.

Oligonucleotide probes. 14 SSOs were used for DRB1 generic typing, 8 for DR4 subtyping, 12 for DQB, and 8 for DQA typing. These probes were synthesized in our laboratory using the sequences reported by Tiercy et al. $(25,26)$.

Statistical analysis. The odds ratio was calculated according to Woolf's formula and, by convention, expressed as a relative risk (RR). Haldane's modification of the formula was used when one element of the equation was zero. The statistical significance of the difference of RR from unity was tested by chi-square analysis with one degree of freedom using the formula: $\chi^{2}=(1 / V)\left(\log _{e} R R\right)^{2}$, where $V$ is the sampling variance (27). The level of significance was set to $0.05 . P_{c}$ indicates a $P$ value corrected by use of Bonferonni inequality method, by multiplying $P$ by the number of alleles compared. Gene frequencies $(g)$ were calculated from the observed allele frequencies $(f)$ using the formula: $g=1-\vee(1-f)$

Different groups of IDDM patients were compared according to various clinical or biological parameters using chi-square analysis with Yates' correction when appropriate.

\section{Results}

\section{Positive associations of class II alleles with IDDM}

Distribution of $D R B, D Q B$, and $D Q A$ alleles. The distribution of DRB1, DQA1, and DQB1 alleles among the 405 healthy controls was comparable to that in previous reports and closely matched with the expected frequencies in Caucasoid individuals (Table II), indicating that our population was in HardyWeinberg equilibrium. When all the IDDM patients (children and adults) were considered as a whole, the well-known positive association of DR3 and DR4 with IDDM in Caucasians was confirmed: $86.1 \%$ of the patients were DR3 and/or DR4 compared with only $44.1 \%$ of the healthy controls. However, when the pediatric and adult patients were compared, we found a significant difference in some class II risk alleles according to age at clinical onset. The HLA DR3 allele was present in $52 \%$ of the adults compared with only $26 \%$ in the controls $(P<0.005)$ and $69 \%$ in childhood IDDM. The prevalence of the HLA DR4 allele was $48 \%$ in the adult patients (controls: $20 \%, P<0.005$ ) and $66 \%$ in the pediatric patients (Table II, top). Similar differences were found between the adult and child patients with regard to $\mathrm{DQB} 1{ }^{*} 0201$ and 0302 alleles ( Table II, middle) as well as DQA1*0301 (Table II, bottom). An age gradient was established, indicating that the DR3/4 frequency significantly decreased with the age of IDDM onset (Fig. 1), whereas the proportion of non-DR3/non-DR4 subjects increased. Among the children aged $<15 \mathrm{yr}$ at onset, $37.5 \%$ were $\mathrm{DR} 3 / 4$ heterozygotes $(R R=23.4)$ and $97.3 \%$ possessed the DR3 and/or DR4 alleles. These high frequencies are similar to those usually reported in the literature. Conversely, only $17.9 \%$ of the adult-onset diabetics were DR3/4 heterozygotes $(\mathrm{RR}=8.5)$, and only $81.7 \%$ possessed the DR3 and/or DR4 alleles $\left(P_{c}<0.001\right.$ relative to the children $)$. Patients $>30$ $\mathrm{yr}$ at the time of onset were non-DR3/non-DR4 in $25.8 \%$ of cases (Table III).

The DR3-associated susceptibility was significant in both the adult $(R R=2.97)$ and pediatric $(R R=6.11)$ patients. It was abolished in heterozygous patients when combined with DR2 $(2.1 \%$ of adults, $1.8 \%$ of children, and $1.9 \%$ of normal controls) or DR11 alleles (1.7, 2.7, and 3.3\%, respectively). A
Table II. Distribution of DRB1, DQB1, and DQA1 Alleles among Adult-onset IDDM Patients, Diabetic Children, and Control Subjects

\begin{tabular}{|c|c|c|c|c|c|}
\hline & \multirow{2}{*}{$\begin{array}{l}\text { Controls } \\
(n=405)\end{array}$} & \multicolumn{2}{|c|}{ Adult onset IDDM } & \multicolumn{2}{|c|}{ Childhood onset IDDM } \\
\hline & & $(n=290)$ & $\mathbf{R R}$ & $(n=112)$ & $\mathbf{R} \mathbf{R}$ \\
\hline \multicolumn{6}{|l|}{ DRB1 } \\
\hline DR1 & 24.3 & 15.9 & & 10.7 & \\
\hline DR2 & 26.2 & 11.7 & $0.34^{\ddagger}$ & 5.4 & $0.16^{\ddagger}$ \\
\hline DR3 & 26.5 & 51.7 & $2.97^{\S}$ & 68.8 & $6.11^{5}$ \\
\hline DR4 & 20.1 & 47.9 & $3.65^{\S}$ & 66.1 & $7.75^{8}$ \\
\hline DR 11 & 19.4 & 10.3 & & 5.4 & \\
\hline DR 12 & 2.7 & 1.4 & & 0.9 & \\
\hline DR 13 & 22.3 & 18.6 & & 6.3 & $0.23^{*}$ \\
\hline DR 14 & 7.1 & 0.7 & & 0.9 & \\
\hline DR7 & 24.8 & 15.2 & & 6.3 & $0.21^{*}$ \\
\hline DR8 & 4.9 & 4.8 & & 3.6 & \\
\hline DR9 & 2 & 2.4 & & 4.5 & \\
\hline DR 10 & 2.5 & 0.7 & & 1.8 & \\
\hline \multicolumn{6}{|l|}{ DQB1 } \\
\hline 501 & 31.6 & 17.1 & $0.44^{*}$ & 11.3 & $0.28^{*}$ \\
\hline 502 & 8.8 & 4.5 & & 4.2 & \\
\hline 503 & 5.6 & 1.9 & & 1.4 & \\
\hline 601 & 1.9 & 0.7 & & 0 & \\
\hline 602 & 18.6 & 4.8 & $0.22^{\ddagger}$ & 2.8 & $0.13^{8}$ \\
\hline 603 & 16.3 & 4.5 & $0.24^{\ddagger}$ & 0 & \\
\hline 604 & 7 & 9.3 & & 5.6 & \\
\hline 201 & 34.4 & 63.2 & $3.27^{\S}$ & 74.6 & $5.60^{\S}$ \\
\hline 301 & 34.4 & 19.7 & $0.47^{*}$ & 11.3 & $0.24^{*}$ \\
\hline 302 & 11.6 & 43.1 & $5.77^{\S}$ & 59.2 & $11.05^{\S}$ \\
\hline 303 & 6.5 & 3 & & 1.4 & \\
\hline 402 & 4.2 & 5.2 & & 0 & \\
\hline \multicolumn{6}{|l|}{ DQA 1} \\
\hline 101 & 36.3 & 18.2 & $0.39^{\ddagger}$ & 11 & $0.22^{*}$ \\
\hline 102 & 33 & 19.3 & & 12.3 & \\
\hline 103 & 17.2 & 5.2 & $0.26^{\ddagger}$ & 0 & \\
\hline 201 & 19.5 & 14.5 & & 8.2 & \\
\hline 301 & 22.3 & 50.9 & $3.61^{\S}$ & 74 & $9.91^{8}$ \\
\hline 401 & 4.2 & 5.6 & & 0 & \\
\hline 501 & 40.9 & 64.7 & $2.65^{\S}$ & 68.5 & $3.14^{\ddagger}$ \\
\hline 601 & 0.5 & 0 & & 0 & \\
\hline
\end{tabular}

Results are presented as percent of groups. $R \mathbf{R}$, relative risk. Only statistically significant $\mathrm{RR}$ are presented: ${ }^{*} P_{c}<0.05,{ }^{\ddagger} P_{c}$ $<0.005 ;{ }^{\S} P_{c}<0.0005$.

significant increase in homozygous patients carrying the DR3 genotype in double dose was observed in both the adult patients ( 8.6 vs. $0.7 \%$ in controls, $\left.R R=13.4, P_{c}<0.001\right)$ and the pediatric patients $\left(11.6 \%, \mathrm{RR}=18.6, P_{c}<0.001\right)$. However, the frequency of DR3 homozygotes was not higher than that calculated from the DR3 gene frequency in these patient groups. In addition, it cannot formally be excluded that some patients identified as homozygous were in fact heterozygous with a "blank" haplotype, since family typing was not systemically performed in these cases.

DR4 was significantly associated with adult- and childhood-onset IDDM ( $R R=3.65$ and 7.75, respectively), except in the presence of the DR2 allele, whose protective action over- 


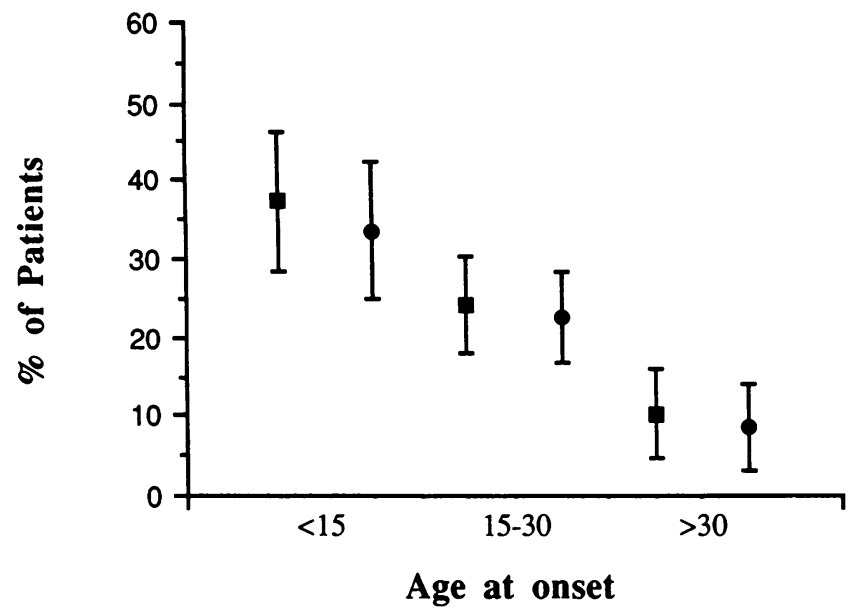

Figure 1. Age gradient of DR3/4 and DQB1 *0201/0302 frequencies in childhood and adult-onset IDDM patients. $(\bullet)$ DR3/4 patients (匹) DQB1 *0201 /0302 patients. Results are given as percent of age groups $\pm 95 \%$ confidence interval.

came the DR4 susceptibility effect (DR2/4: $3.4 \%$ of adult patients, $3.3 \%$ of pediatric patients, and $2.7 \%$ of controls). It is noteworthy that the frequency of DR4 homozygous patients was not significantly different from that in the healthy control group $(6.2 \%$ in adult diabetics, $7.1 \%$ in children, and $1.2 \%$ in controls, NS).

It has been reported that the DR 1/4 heterozygous genotype is significantly increased in IDDM patients, although DR4 was linked to the DQB $1 * 0301$ protective allele (28). This was not observed in our two patient groups $(4.5 \%$ in adults and $4.4 \%$ in children vs. $3.7 \%$ in controls), in which the DR1/4 combination was neutral.

The distribution of DRB1 alleles in non-DR3/non-DR4 IDDM patients strictly paralleled that in normal controls. Thus, no significant increase of any particular DRB1 allele was observed.

DQB $1 * 0201$ was significantly associated with IDDM in both groups of patients. This susceptibility was abolished when DQB $1 * 0201$ was paired with the protective DQB $1 * 0602$ allele

Table III. Age-dependent Genetic Heterogeneity among the IDDM Patients

\begin{tabular}{lcccr}
\hline & \multicolumn{3}{c}{ IDDM patients } & \\
\cline { 2 - 4 } \multicolumn{1}{c}{$\begin{array}{c}\text { Age at } \\
\text { clinical onset }\end{array}$} & $\begin{array}{c}<15 \mathrm{yr} \\
(n=112)\end{array}$ & $\begin{array}{c}15-30 \mathrm{yr} \\
(n=183)\end{array}$ & $\begin{array}{c}>30 \mathrm{yr} \\
(n=107)\end{array}$ & $\begin{array}{r}\text { Controls } \\
(n=405)\end{array}$ \\
\hline $\mathrm{DR} 3 / \mathrm{X}$ & $68.8 \pm 8.5$ & $54.5 \pm 7.2$ & $44.8 \pm 9.4$ & $26.5 \pm 4.2$ \\
DR4/X & $66.1 \pm 8.7$ & $56.8 \pm 7.1$ & $39.6 \pm 9.2$ & $20.1 \pm 3.9$ \\
DR3/4 & $37.5 \pm 8.9^{*}$ & $24.2 \pm 6.2$ & $10.3 \pm 5.7^{*}$ & $2.5 \pm 1.5$ \\
DR3 and/or 4 & $97.3 \pm 3.0^{\ddagger}$ & $87.1 \pm 4.8$ & $74.2 \pm 8.2^{\ddagger}$ & $44.1 \pm 4.8$ \\
non-DR3/non-DR4 & $2.7 \pm 2.5^{\S}$ & $12.9 \pm 4.8$ & $25.8 \pm 82^{\S}$ & $55.9 \pm 4.8$ \\
DQB1*0201/0302 & $33.6 \pm 8.7^{*}$ & $22.6 \pm 6.0$ & $8.6 \pm 5.3^{*}$ & $2.3 \pm 1.4$ \\
& & & & \\
\hline
\end{tabular}

Results are presented as percent of age groups $\pm 95 \%$ confidence interval.

Chi-square analysis for comparison between patients with and without the given age and phenotype. ${ }^{*} P<0.001,{ }^{\ddagger} P<0.0005,{ }^{\S} P$ $<0.005$.
( $1.5 \%$ of adult patients, $1.4 \%$ of children, and $3.3 \%$ of controls, NS). It seems unlikely, however, that DQB $1{ }^{*} 0201$ alone is the susceptibility allele since the same allele is present in the protective DR7-DQB1 *0201 haplotype.

The DQB1 *0302 allele was a strong risk factor, whatever the associated allele. The degree of susceptibility conferred by the DQB 1 *0302 allele in both the heterozygous and the homozygous state was the highest among all the DQB alleles, with an RR of 5.8 in adult patients and of 11.05 in pediatric patients. The DQB1 *0302/0201 combination was observed in $18.4 \%$ of adult-onset patients versus $33.6 \%$ of pediatric patients and $2.3 \%$ of controls. An age gradient was established, similar to that observed for the DR3/4 genotype (Table III and Fig. 1). Even the combination to the protective $\mathrm{DQB} 1{ }^{*} 0602$ allele did not fully abolish the DQB $1 * 0302$-associated susceptibility ( $1.1 \%$ of adult diabetics and $1.4 \%$ of children vs. $0 \%$ of controls), indicating that the influence of DQB $1{ }^{*} 0302$ could be dominant.

DR4 subtypes associated with IDDM. The above results of DR4 typing were obtained using a probe that hybridizes with a sequence common to all DR4 subtypes (0401-0408). However, characterization of DR4 subtypes using specific probes in both adult- and childhood-onset patients revealed that the DRB1 *0402 (Dw10) and 0405 (Dw15) alleles were strongly associated with the disease $(\mathrm{RR}=15.4$ and 18.1 , respectively, $P_{c}<0.05$ ), whereas DRB1*0401 (Dw4) was neutral (RR $=0.9)$ and DRB1 *0404 (Dw14) had a significant protective effect $(\mathrm{RR}=0.26)$ (Table IV). Although differences between adult and pediatric groups were not significant, a tendency for an increase of DRB ${ }^{*} 0402$ allele in adults ( 22.9 vs. $14 \%$ in children and 5.6\% in controls) and a decrease of DRB1 *0401 ( $41.6 \%$ in adults vs. $50.9 \%$ in children and $50.4 \%$ in controls) was observed. This observation differs from previous reports suggesting that DRB1*0401 is the most frequent allele in DR4-positive IDDM patients $(5,29)$. The results concerning DRB 1*0405 were particularly interesting: $19.2 \%$ of the DR4-positive patients (both in adult and child diabetics) expressed this allele, which is not usually found in Caucasian populations. When the frequencies of DRB1 *0401, 0402, and 0405 in all IDDM patients were combined, the RR reached statistical significance $(R R=5.5)$. Taken together, DRB1 *0402 and 0405 gave a highly significant risk of 27.9.

Table IV. DR4 Subtyping

\begin{tabular}{|c|c|c|c|}
\hline & \multicolumn{2}{|c|}{$\begin{array}{l}\text { Percentage of DR4- } \\
\text { positive subjects }\end{array}$} & \multirow[b]{2}{*}{$\mathbf{R R}$} \\
\hline & $\begin{array}{l}\text { IDDM patients* } \\
\quad(n=213)\end{array}$ & $\begin{array}{l}\text { Controls } \\
(n=81)\end{array}$ & \\
\hline DRB1*0401 (DW4) & 41.8 & 50 & \\
\hline $\mathrm{DRB}^{*} 0402$ (DW 10) & 20.5 & 2.4 & 15.4 \\
\hline DRB $1 * 0403$ (DW13) & 3.4 & 9.5 & \\
\hline DRB $1 * 0404$ (DW14) & 13 & 35.7 & 0.26 \\
\hline DRB1*0405 (DW15) & 19.2 & 2 & 18.1 \\
\hline $\mathrm{DRB} 1 * 0406$ & 0 & 2.4 & \\
\hline DRB 1* 0407 & 2 & 0 & \\
\hline DRB1*0408 & 0.6 & 0 & \\
\hline
\end{tabular}

Results are presented as percent of groups. * Adult $(n=139)$ and pediatric $(n=74)$ patients. 
Table V. Distribution of DQB Alleles among DR4-positive Subjects

\begin{tabular}{|c|c|c|}
\hline & $\begin{array}{c}\text { IDDM }^{*} \\
(n=213)\end{array}$ & $\begin{array}{l}\text { Controls } \\
(n=81)\end{array}$ \\
\hline DQB1* 0302 & 90.8 & 57 \\
\hline $\mathrm{DQB} 1 * 0301$ & 9.2 & 43 \\
\hline DRB1* 0401-DQB1*0302 & 38.2 & 19.2 \\
\hline DRB1*0401-DQB1*0301 & 3.51 & 30.7 \\
\hline DRB1* 0402-DQB1* 0302 & 20.5 & 2.4 \\
\hline DRB $1 * 0402-D Q B 1 * 0301$ & 0 & 0 \\
\hline DRB1* 0404-DQB1* 0302 & 13 & 35.7 \\
\hline DRB1* 0404-DQB1* 0301 & 0 & 0 \\
\hline DRB1* 0405-DQB1* 0302 & 19.2 & 2 \\
\hline DRB1* 0405-DQB1* 0301 & 0 & 0 \\
\hline
\end{tabular}

Results are presented as the percent of DQB1 alleles in the DR4-positive subjects. * Adult- and childhood-onset patients.

Given the $0.25-0.50 \%$ incidence of IDDM in French Caucasoids (30), the absolute risk for individuals expressing this genotype is $1: 18$.

Among the DR4 haplotypes, DQB 1*0302 has been reported to be associated with $\operatorname{IDDM}(3,6,28)$. Indeed, $91 \%$ of the DR4 adult and $89.5 \%$ of the DR4 pediatric IDDM patients possessed this allele compared with only $57 \%$ of the DR4 controls ( Table V). Nevertheless, DQB $1{ }^{*} 0302$ could not account alone for the susceptibility observed among DR4-positive patients, since DRB ${ }^{*} 0404$, which was always linked to DQB 1*0302, was protective, and DRB1*0401, which was linked to DQB1 ${ }^{*} 0302$ in $91.6 \%$ of cases, was not significantly associated with susceptibility.

The highest risk for developing IDDM was found in heterozygous individuals carrying the DR3-DQB1 *0201 haplotype together with the DRB $1 * 0402$ or $0405-\mathrm{DQB} 1{ }^{*} 0302$ haplotype. Although this genotype concerned only $8.3 \%$ of the IDDM patients (none of the healthy controls), it provided an RR of 40.05 .

\section{Negative associations of class II alleles with IDDM}

HLA-DR2 was protective against IDDM in adult patients ( RR $=0.34)$ unless it was combined with DR3 $(R R=0.85)$ or DR4 $(\mathrm{RR}=0.97)($ Table $\mathrm{VI})$. A profound protective effect was observed in combination with any other DRB1 allele (DR2/X: $\left.\mathrm{RR}=0.18, P_{c}<0.0005\right)$. Interestingly, this protective effect was not as strong as in childhood-onset diabetics $(R R=0.16)$.
Two main haplotypes have been identified among DR2 subjects on the basis of sequence polymorphism: DRB $1 * 1501$ (Dw2)-DRB5*0101-DQB1 *0602 and DRB1*1601 (Dw21$\mathrm{AZH}$ )-DRB5 ${ }^{*} 0201-\mathrm{DQB} 1{ }^{*} 0502$. The former (Dw2) has been reported to be protective whereas the latter (Dw21-AZH) is usually associated with $\operatorname{IDDM}(5,31,32)$. Results obtained in this study confirm the protective role of DR15 (deduced haplotype from DQB1 *0602), although less strikingly than in the diabetic children: $4.8 \%$ of the adult IDDM patients were DR2-DQB1 *0602 compared with $18.6 \%$ of the normal controls $(R R=0.22)$ and $2.8 \%$ of the diabetic children ( $R R$ $=0.13$ ). The significant protective effect of DQB1 ${ }^{*} 0602$ was observed in all the heterozygous combinations, except with DQB1 *0302.

Surprisingly, the DR16 (Dw21-AZH)-DQB1 *0502 haplotype was not significantly more frequent in our adult patients. Thus, in the DR2 subgroup, only $38.5 \%$ of the adult-onset IDDM patients were DR16-DQB $1{ }^{*} 0502$ versus $33.6 \%$ of the normal controls (NS) and $77.8 \%$ of the diabetic children. This observation contrasts with previous reports showing a strong association of this haplotype (rarely found in the normal population) with the disease.

Two of the DR2 adult IDDM patients had a DQB1 gene different from those usually found in healthy DR2 individuals. Instead of DQB $1{ }^{*} 0602$ or 0502 , the DQB $1{ }^{*} 0402$ allele was present in both cases, in association with the DQA1 *0401 allele. The occurrence of such recombinant haplotypes between DQA and DR subregions should be confirmed by family typing, although it has recently been found in two other DR2 IDDM patients (33). No recombinant haplotype was observed in our DR2 controls.

With regard to the DR 13 haplotypes (overall RR of 0.79 for adult patients), DQA and DQB genotyping allow to differentiate the $\mathrm{DRB} 1 * 1301-\mathrm{DQB} 1 * 0603-\mathrm{DQA} 1{ }^{*} 0103$ and the DRB1*1302-DQB1 *0604-DQA1*0102 haplotypes (34). The latter has been reported to be associated with IDDM, whereas it was neutral in our study in both groups of diabetic patients, contrasting with a protective effect of the former ( RR $\left.=0.24, P_{c}<0.005\right)$. Finally, the DR7 haplotype was found to be protective only in childhood-onset diabetic patients ( RR $\left.=0.21, P_{c}<0.005\right)$.

\section{Role of residue 57 of the $D Q \beta$ chain}

The presence at position 57 of the outer domain of the $\mathrm{DQ} \beta$ chain of either charged (Asp) or neutral (Val, Ser, or Ala) residues has been investigated (11). 64\% of the adult-onset patients were homozygous for the absence of Asp at position 57

Table VI. Negative Associations with IDDM

\begin{tabular}{|c|c|c|c|c|c|}
\hline & $\begin{array}{l}\text { Controls } \\
(n=405)\end{array}$ & $\begin{array}{l}\text { Adult-onset IDDM } \\
\quad(n=290)\end{array}$ & $\mathbf{R R}$ & $\begin{array}{l}\text { Childhood-onset IDDM } \\
\qquad(n=112)\end{array}$ & $\mathbf{R} \mathbf{R}$ \\
\hline DR2 & 26.2 & 11.7 & 0.34 & 5.4 & $0.16^{\ddagger}$ \\
\hline DQB1* 0602 (DW2) & 71.0 & 41.0 & 0.22 & 51.8 & $0.13^{5}$ \\
\hline DQB1*0502 (DW21-AZH) & 33.6 & 38.5 & & 77.8 & \\
\hline DR 13 & 22.3 & 18.6 & & 6.3 & $0.23^{*}$ \\
\hline DQB1* 0603 (DW18) & 73.1 & 24.2 & $0.24^{\ddagger}$ & 0 & \\
\hline DQB1* 0604 (DW19) & 31.4 & 50.0 & & 88.9 & \\
\hline DR7 & 24.8 & 15.2 & & 6.3 & $0.21^{*}$ \\
\hline
\end{tabular}

Results are presented as percent of groups. ${ }^{*} P_{c}<0.05 .{ }^{\ddagger} P_{c}<0.005 .{ }^{\circledR} P_{c}<0.0005$. 
Table VII. Nature of Amino Acid at Position 57 of the DQß Chain

\begin{tabular}{|c|c|c|c|c|c|}
\hline Amino acid at position 57 & $\begin{array}{l}\text { Healthy } \\
\text { controls } \\
(n=405)\end{array}$ & $\begin{array}{l}\text { Adult-onset } \\
\text { IDDM } \\
(n=290)\end{array}$ & $\begin{array}{c}\mathbf{R R}^{*} \\
\text { (95\% confidence limits) }\end{array}$ & $\begin{array}{l}\text { Childhood-onset } \\
\operatorname{IDDM}(n=112)\end{array}$ & $\begin{array}{c}\mathrm{RR}^{*} \\
\text { (95\% confidence limits) }\end{array}$ \\
\hline Asp, Asp or Asp, blank ${ }^{\ddagger}$ & 26.5 & 5.3 & $0.16(0-0.51)$ & 5.6 & $0.16(0-0.58)$ \\
\hline $\begin{array}{l}\text { Asp, non-Asp } \\
\text { non-Asp, non-Asp or }\end{array}$ & 47.4 & 31.1 & $0.501(0.29-0.70)$ & 23.9 & $0.35(0.06-0.64)$ \\
\hline non-Asp, blank & 25.6 & 63.7 & $5.1(4.9-5.3)$ & 71.8 & $7.4(7.18-7.62)$ \\
\hline Any haplotype including & & & & & \\
\hline 1 Asp allele & 74 & 36.4 & $0.2(0.03-0.36)$ & 29.5 & $0.15(0-0.41)$ \\
\hline Any haplotype including & & & & & \\
\hline 1 non-Asp allele & 73 & 94.8 & $6.60(6.46-6.74)$ & 95.7 & $8.44(8.23-8.65)$ \\
\hline
\end{tabular}

Results are presented as percent of groups. ${ }^{*} P_{c}<0.005 .{ }^{\ddagger}$ Blank indicates either homozygosity for Asp-bearing allele, or the presence of an unidentified allele.

versus $72 \%$ of the pediatric group and $26 \%$ of the healthy controls ( Table VII). This figure, particularly in the adult group, is significantly lower than in previous studies, most of which mainly included children. An age-dependent gradient similar to that for the prevalence of DR3/DR4 was also found for the presence of at least one Asp residue at position 57 (30\% of the diabetic children, $32 \%$ of the adults $<30 \mathrm{yr}, 45 \%$ of those $>30$ yr, and $74 \%$ of the controls). Homozygosity for Asp-positive alleles was lower in the diabetic children (5\%) than in the older adults (12\%) and controls (26\%). All the Asp/Asp homozygous patients (adults and children) were non-DR3/non-DR4, although all the non-DR3/non-DR4 children were Asp/Asp homozygotes compared with only $23 \%$ of the non-DR3/nonDR4 adult patients.

Among the DQB1 alleles with a non-Asp residue 57, only DQB $1 * 0302$ and 0201 (both with Ala) were associated with adult-onset IDDM. The DQB1 *0201 allele was probably not solely responsible for IDDM susceptibility since it was associated with either the DR7 (protective) or DR3 (risk) haplotype. DQB1 *0502 and 0604 did not confer significant susceptibility; indeed, DQB 1 *0501 was associated with a protective effect. Three DQB1 alleles carrying an Asp at position 57 were associated with a protective effect $(\mathrm{DQB} 1 * 0602,0603$, and 0301 ). The protection confered by DQB1 *0503, 0601 , or 0303 alleles did not reach statistical significance. Lastly, the DQB $1 * 0402$ allele was neutral.

$D Q A$ locus

In all the IDDM and control subjects studied, the DQA alleles strictly matched those expected on the basis of the known linkage disequilibria between the DRB, DQB, and DQA subregions. Therefore, the increased DQA $1{ }^{*} 0301$ and DQA $1{ }^{*} 0501$ frequencies in the IDDM patients was directly related to that of DRB 1 *04-DQB 1 *0302 and DRB1 *03-DQB1 *0201 haplotypes, respectively. Similarly, the decrease in DQA 1 *0103 was directly associated with that of the DRB1 *13-DQB1 *0603 haplotype. In particular, the frequency of the Arg residue in position 52 of the DQ $\alpha$ chain, which has recently been incriminated in IDDM susceptibility (35), was directly linked to that of the DR3 and/or DR4 IDDM susceptibility alleles. All the diabetic patients and healthy controls with non-Asp residues at $\mathrm{DQ} \beta 57$ and Arg residues at DQ $\alpha 52$ were DR3 or DR4 homozygotes or DR3/4 heterozygotes.
It thus appears that DQA oligotyping in Caucasians does not itself improve the predictive value of risk determination in terms of protection or susceptibility to disease, even when combined with an Asp at position 57 of the $\mathrm{DQ} \beta$ chain.

\section{Clinical and immunological correlations}

Because of the marked genetic differences between the adult and child diabetics, who all presented as type 1 IDDM, 190 adult-onset patients included in a Cs-A therapeutic trial were analyzed in particular detail according to their genotype (Table VIII). All presented with recent weight loss, polyuria, and ketosis or ketoacidosis. The mean age at onset, duration of clinical symptoms, initial glucose blood level, and insulin needs were not significantly different in non-DR3/non-DR4 from those in DR3 and/or DR4 patients. A tendency towards a less frequent family history of IDDM and a more frequent family history of NIDDM was found in non-DR3/non-DR4 patients in comparison to patients carrying other genotypes, but the differences were not statistically significant. The degree of weight loss was also less marked in these patients. Furthermore, the frequency of ICA was considerably lower ( 20 vs. $64.7 \%$ in the DR3 and/ or DR4 patients and $69 \%$ in the diabetic children, $P_{c}<0.0001$ )

Table VIII. Clinical and Immunological Correlations with HLA Genotype in 190 Adult-onset IDDM Patients*

\begin{tabular}{lcccc}
\hline & $\begin{array}{c}\text { DR3/4 } \\
(n=38)\end{array}$ & $\begin{array}{c}\text { DR3/X } \\
(n=62)\end{array}$ & $\begin{array}{c}\text { DR4/X } \\
(n=60)\end{array}$ & $\begin{array}{c}\text { non-DR3/ } \\
\text { non-DR4 } \\
(n=30)\end{array}$ \\
\hline Percent & 20 & 32.6 & 31.6 & 15.8 \\
Age at onset (yr) & $24.3 \pm 6.6$ & $25.1 \pm 7.8$ & $26.7 \pm 10.3$ & $29.08 \pm 10.5$ \\
Duration of clinical & & & & \\
$\quad$ symptoms (wk) & $6.9 \pm 5.6$ & $9.1 \pm 10.7$ & $8.5 \pm 5.6$ & $3.7 \pm 4.9$ \\
Weight loss $\geq 10 \%(\%)$ & 62.1 & 44.4 & 35.4 & $23.3^{\ddagger}$ \\
Ketoacidosis (\%) & 16.2 & 6.5 & 17.4 & 10.7 \\
Family history (\%) & & & & \\
$\quad$ IDDM & 21 & 21.3 & 25 & 13.3 \\
$\quad$ NIDDM & 26.9 & 25.5 & 19.2 & 33.3 \\
ICA (\% positive) & 62.2 & 59.1 & 66.7 & $20.0^{\ddagger}$ \\
IAA (\% positive) & 21 & 45.1 & 26.6 & 20 \\
& & & & \\
\hline
\end{tabular}

Time values are presented as mean \pm SD.

* Subgroup of Cs-A-treated patients, representative of the whole adult-onset IDDM group. ${ }^{\ddagger} P_{c}<0.01$ vs. other groups. 
for a similar duration of overt disease. No difference was found with regard to the presence of IAA before insulin therapy between DR3/4 and non-DR3/non-DR4 patients (21 and 20\% of cases, respectively). A higher but not significant frequency of IAA in DR3/X patients was noted. The distribution of DRB1 alleles among non-DR3/non-DR4 patients showed an identical frequency of DR13, DR7, DR2, and DR1 (33\% each). DQB1*0301, 0501, 0201, and 0602, alleles usually found to be protective, represented $46,43,36$, and $26 \%$, respectively, of the DQB1 alleles. An unusual haplotype, which cannot be deduced from the linkage disequilibrium observed in healthy individuals, was observed in only one patient (DR13DQA1 ${ }^{*} 0201-D Q B 1{ }^{*} 0201$ ). 10 of these 30 non-DR3/nonDR4 patients were Asp homozygotes at position 57 of the DQ $\beta$ chain.

\section{Discussion}

The clinical heterogeneity of diabetes mellitus has long been known but it is only relatively recently that diabetic patients were classified into two categories according to insulin dependency (17). This distinction between type 1 IDDM and type 2 NIDDM has received major support from accumulating evidence that an autoimmune reaction is directly involved in the destruction of insulin-secreting $\beta$ cells characterizing IDDM. However, difficulties still persist in the clinical classification of diabetes mellitus because of the existence of confusing forms of the disease such as maturity-onset diabetes of the young and non-insulin-requiring slow type 1 diabetes (36) of autoimmune origin (37). Moreover, circumstantial observations of IDDM of toxic, viral, or unknown origin (in the absence of any immune abnormality) raise the possibility that IDDM may encompass a heterogeneous syndrome with a variety of origins (38). The development of immunological markers for antiislet autoimmunity, as well as the recent availability of molecular markers to characterize genetic susceptibility at the DNA level, has generated a new approach for discriminating between various forms of $\beta$ cell destruction. We now report evidence favoring the heterogeneity of IDDM based on the use of the HLA markers at the genomic level after PCR amplification.

Studying a group of 290 IDDM patients in whom clinical disease occurred after the age of 15 , we observed significant differences in HLA genotypes relative to previous pediatric reports and to a group of 112 diabetic children analyzed simultaneously using class II oligonucleotide typing.

Like the childhood-onset diabetics, the adult-onset IDDM patients showed a significantly higher frequency of DR3 and DR4 haplotypes, as well as a lower frequency of DR2, DR7, and DR 13 (protective) haplotypes. However, the frequency of DR 3 and / or DR 4 patients, particularly in the DR3 / 4 heterozygous combination, was significantly lower and that of nonDR3/non-DR4 patients significantly higher in the adult- than in childhood-onset patients. These two trends were already apparent in the 15-30-yr age group and even more marked in the group aged $>30 \mathrm{yr}$.

The risk associated with a combination of the two transallelic markers exceeded that of homozygosity for DR4 but was similar to that in patients homozygous for DR3. This observation strongly argues in favor of a synergistic effect between independent susceptibility alleles and confirms the special permissive role of DR3. The highly predisposing influence of the DR3/4 genotype is also indicated by the highest rate of disease concordance in DR3/4 sibling pairs and monozygotic twins (39). It can be assumed in such patients that strong predisposing immunological factors linked to the DR3 and DR4 haplotypes trigger the disease early in life, explaining the predominance of DR3/4 patients in the childhood-onset group (40). Conversely, IDDM would be more heterogeneous in adults than in children, as in this study, probably because in the absence of the strongly penetrant DR3/4 genotype the HLA contribution is more diluted by the effect of other genes and by environmental or other acquired factors.

The analysis of class II alleles confirms this age-dependent susceptibility gradient. Restriction fragment length polymorphism and oligotyping studies have focused on the responsibility of the DQB locus in IDDM predisposition. The DQB $1{ }^{*} 0602$ and 0603 alleles have been assumed to be involved in protection against diabetes, whereas DQB $1{ }^{*} 0302$ is considered the major candidate susceptibility gene. Our findings confirmed these data in both age groups with, however, a lower frequency of $\mathrm{DQB1}{ }^{*} 0302$ and a higher frequency of DQB $1{ }^{*} 0602$ and 0603 in adult-onset than in childhood-onset IDDM patients. Furthermore, mapping of protective or susceptibility genes to the $\mathrm{DQB}$ locus rather than to the DRB locus was not apparent from our data. First, the DQB1 *0302 gene was present in only $46.5 \%$ of these Caucasian patients versus $11.6 \%$ of healthy individuals. Second, among the DR4DQB $1 * 0302$ haplotypes, susceptibility to IDDM varied considerably and only DRB $1{ }^{*} 0402$ and DRB $1{ }^{*} 0405$ were closely associated with the disease. This observation, which contrasts with most previous findings, was made in both patient age groups. DR4 subtypes differ at positions $67-71$ of the outer domain of the $\mathrm{DR} \beta$ chain. This region, which has been implicated in susceptibility to rheumatoid arthritis and pemphigus vulgaris $(6,41,42)$ could thus also play a role in IDDM. Finally, even if it is likely that the DQB locus participates in disease onset in DR4-positive haplotypes, this is probably not the case for non-DR4 haplotypes: the same DQB1 *0201 allele was found on the susceptible DR3 haplotype and on the protective DR7 haplotype. Thus, any other gene on the DR 3 haplotype is a potential susceptibility candidate.

Another interesting approach to the predisposing class II alleles has been to search for predisposition residues on DQ $\alpha$ and $\mathrm{DQ} \beta$ chains. The presence of a negatively charged residue at position 57 of the $\mathrm{DQ} \beta$ chain has thus been reported to confer resistance to disease, whereas a neutral residue is thought to be permissive. We confirmed that Asp residue 57 is less common in childhood- and adult-onset IDDM than in healthy controls, although the difference was more clearcut in the children. Up to $36.4 \%$ cases of adult-onset IDDM and $44.8 \%$ of the patients with onset after $30 \mathrm{yr}$ had at least one Asp residue at position 57 of the $\mathrm{DQ} \beta$ chains, whereas only $63.7 \%$ were homozygous for non-Asp alleles. Only 6 of the 112 children studied were Asp homozygous, representing all the nonDR3/non-DR4 children. The relative risk associated with non-Asp $D Q \beta 57$ residues was not higher than that of the susceptibility alleles on the DRB and DQB loci. The fact that Asp 57 , in the homozygous or heterozygous state, was found in as many as $36.4 \%$ of the IDDM patients (vs. $74 \%$ of normal controls) suggests that the protection associated with Asp 57 is recessive.

Finally, residue 57 should probably be considered as an element of a composite recognition structure in which different 
polymorphic sites in class II molecules act in concert to determine disease susceptibility. This agrees with the concept that several DQ $\alpha \beta$ heterodimers (in cis or in trans), or possibly $\mathrm{DQ} \alpha \mathrm{DR} \beta$ heterodimers, may be associated with IDDM susceptibility or protection, by differential binding of diabetogenic peptides to HLA molecules (43-46).

The genetic contribution of the DQA locus in Caucasians may be interpreted in this sense, rather than by considering it as a primary susceptibility determinant. In our study, DQA alleles did not confer a greater risk than $\mathrm{DQB}$, with which it shows strong linkage disequilibrium. The presence of two Arg residues at position 52 of the $\mathrm{DQ} \alpha$ chain and non-Asp residues at position 57 of the DQ $\beta$ chain in IDDM patients (35) could thus be exclusively related to the linkage disequilibrium with DR3 and/or DR4 alleles. We found that only $32 \%$ of the IDDM patients possessed the four susceptibility molecules, all being DR3/4 heterozygotes or DR3/3 or DR4/4 homozygotes. The DQA contribution is probably different in non-Caucasoid populations, as suggested in Japanese (47) or in Black (48) subjects in whom a particular DQ $\alpha, \beta$ heterodimer, coded either in cis or in trans position, seems to be involved in disease predisposition.

A high frequency of non-DR3/non-DR4 in adult-onset IDDM patients has already been reported in smaller series of patients studied by means of serological HLA-DR typing (49). It was very clearcut in this large study, particularly in patients with onset after the age of $30 \mathrm{yr}$. These non-DR3/non-DR4 patients showed other peculiarities, with a notably low incidence of ICA and less severe disease at onset, raising doubts as to the autoimmune origin in at least some of these patients.

Our data confirm the genetic heterogeneity of patients who present unambiguously with clinical symptoms typical of IDDM and point to a need for complete patient characterization (including accurate HLA typing), particularly in epidemiological or therapeutic studies. They also suggest the existence of other mechanisms in atypical cases (non-DR3/non-DR4 or Asp/Asp patients), as previously done in young black American diabetics (38) and patients with acute necrosis of $\beta$ cells (50). Caution should be used when single HLA markers are employed to predict or exclude the risk for diabetes. In fact, the relative risks show that there are not only one or two predisposing alleles but a whole spectrum of predisposing and protective alleles associated with different relative risks according to age of disease onset.

In closing, it appears that several factors are probably required to trigger IDDM, possibly including relevant sequences in other loci than DR and DQ (51). Preliminary reports have shown some linkage disequilibrium with DP in certain haplotypes (52). Alternatively, quantitative variations in the expression of class II genes, controlled at the level of regulatory segments, could be critical in determining the incidence of IDDM in individuals genetically at risk (53). Non-MHC genes probably play an important role, as recently found in the nonobese diabetic mouse $(54,55)$.

\section{Acknowledgments}

We thank Drs. Bernard Mach, Jean-Marie Tiercy, and Jean-François Eliaou for help with the oligotyping methodology. We also thank Edith Audran, Christine Heinrich, and Patricia Przednowed for their excellent technical assistance.

\section{References}

1. Eisenbarth, G. S. 1986. Type I diabetes mellitus. A chronic autoimmune disease. N. Engl. J. Med. 314:1360-1368.

2. Thomson, G., W. P. Robinson, M. K. Kuhner, S. Joe, M. J. MacDonald, J. L. Gottschall, J. Barbosa, S. S. Rich, J. Bertrams, M. P. Baur, et al. 1988. Genetic heterogeneity, modes of inheritance, and risk estimates for a joint study of Caucasians with insulin-dependent diabetes mellitus. Am. J. Hum. Genet. 43:799-816.

3. Owerbach, D., A. Lemmark, P. Platz, L. P. Ryder, L. Rask, P. Peterson, and J. Ludvigsson. 1983. HLA-D region $\beta$-chain DNA endonuclease fragments differ between HLA-DR identical healthy and insulin-dependent individuals. Nature (Lond.). 303:815-817.

4. Bertrams, J., and M. P. Baur. 1984. Insulin-dependent diabetes mellitus. In Histocompatibility Testing 1984: Report on the Ninth International Histocompatibility Workshop and Conference held in Munich, West Germany, May 1984 and in Vienna, Austria, May 1984. E. D. Albert, M. P. Baur, and W. R. Mayr, editors. Springer-Verlag, Berlin. 348-358.

5. Bach, F. H., S. S. Rich, R. S. Bardosa, and M. Segall. 1985. Insulin-dependent diabetes-associated HLA-D region encoded determinants. Hum. Immunol. 12:59-64.

6. Arnheim, N., C. Strange, and H. Erlich. 1985. Use of pooled DNA samples to detect linkage disequilibrium of polymorphic restriction fragments and human disease: studies of the HLA class II loci. Proc. Natl. Acad. Sci. USA. 82:69706974.

7. Böhme, J., B. Carlsson, J. Wallin, E. Möller, B. Persson, P. A. Peterson, and L. Rask. 1986. Only one DQ $\beta$ restriction fragment pattern of each DR specificity is associated with insulin-dependent diabetes. J. Immunol. 137:941-947.

8. Michelsen, B., and A. Lernmark. 1987. Molecular cloning of a polymorphic DNA endonuclease fragment associates insulin-dependent diabetes mellitus with HLA-DQ. J. Clin. Invest. 79:1144-1152.

9. Sterkers, G., D. Zeliszewski, A. M. Chaussee, I. Deschamps, M. P. Font, C. Freidel, J. Hors, H. Betuel, J. Dausset, and J. P. Levy. 1988. HLA-DQ rather than HLA-DR region might be involved in dominant nonsusceptibility to diabetes. Proc. Natl. Acad. Sci. USA. 85:6473-6477.

10. Baisch, J. M., T. Weeks, R. Giles, M. Hoover, P. Stastny, and J. D. Capra 1990. Analysis of HLA-DQ genotypes and susceptibility in insulin-dependent diabetes mellitus. N. Engl. J. Med. 322:1836-1841.

11. Todd, J. A., J. I. Bell, and H. O. McDevitt. 1987. HLA-DQ $\beta$ gene contributes to susceptibility and resistance to insulin-dependent diabetes mellitus. $\mathrm{Na}$ ture (Lond.). 329:599-604.

12. Horn, G., D. Bugawan, C. Long, and H. A. Erlich. 1988. Allelic sequence variation of the HLA-DQ loci: relationships to serology and to insulin-dependent diabetes susceptibility. Proc. Natl. Acad. Sci. USA. 85:6012-6016.

13. Morel, P. A., J. S. Dorman, J. A. Todd, H. O. McDevitt, and M. Trucco. 1988. Aspartic acid at position 57 of the HLA-DQ $\beta$ chain protects against type I diabetes: a family study. Proc. Natl. Acad. Sci. USA. 85:8111-8115.

14. Ronningen, K. S., T. Iwe, T. S. Halstensen, A. Spurkland, and E. Thorsby. 1989. The amino acid at position 57 of the HLA-DQ $\beta$ chain and susceptibility to develop insulin-dependent diabetes mellitus. Hum. Immunol. 26:215-225.

15. Melton, L. J., III., R. J. Palumbo, and C. P. Chu. 1983. Incidence of diabetes mellitus by clinical type. Diabetes Care. 6:75-86.

16. Angelini, G., C. De Preval, J. Gorski, and B. Mach. 1986. High-resolution analysis of the human HLA-DR polymorphism by hybridization with sequencespecific oligonucleotide probes. Proc. Natl. Acad. Sci. USA. 83:4489-4493.

17. National Diabetes Data Group. 1979. Classification and diagnosis of diabetes mellitus and other categories of glucose intolerance. Diabetes. 29:10391057.

18. Feutren, G., L. Papoz, R. Assan, G. Karsenty, H. Du Rostu, J. Sirmai, B. Vialettes, P. Vexiau, M. Rodier, A. Lallemand, et al. 1986. Cyclosporine increases the role and length of remissions in insulin-dependent diabetes mellitus of recent onset. Lancet. i:119-123.

19. Assan, R., G. Feutren, M. Debray-Sachs, C. Laborie, L. Chatenoud, M. C. Quiniou-Debrie, G. Thomas, and J. F. Bach. 1985. Metabolic immunological effects of cyclosporin in recently type I diabetes mellitus. Lancet. i:67-71.

20. Bottazzo, G. F., A. Florin-Christensen, and D. Doniach. 1974. Islet cell antibodies in diabetes mellitus with autoimmune polyendocrine deficiency. Lancet. ii: $1279-1283$.

21. Pilcher, C., and R. B. Elliott. 1984. Improved sensitivity of islet cell cytoplasmic antibody assay in diabetics. Lancet. i: 1352 .

22. Assan, R., G. Feutren, J. Sirmai, C. Laborie, C. Boitard, P. Vexiau, H. Du Rostu, M. Rodier, M. Figoni, P. Vague, et al. 1990. Plasma C-peptide levels and clinical remissions in recent onset type 1 diabetic patients treated Cyclosporin A and insulin. Diabetes. 39:768-774.

23. Grimberg, J., S. Nawoschik, L. Belluscio, R. McKee, A. Turck, and A. Einsemberg. 1989. A simple and efficient non-organic procedure for the isolation of genomic DNA from blood. Nucleic Acids Res. 17:8390.

24. Saiki, R. K., S. Scharf, F. Faloona, K. B. Mullis, G. T. Horn, H. A. Erlich, 
and N. Arnheim. 1985. Enzymatic amplification of $\beta$-globin genomic sequences and restriction site analysis for diagnosis of sickle cell anemia. Science (Wash DC). 230:1350-1354.

25. Tiercy, J. M., C. Goumaz, B. Mach, and M. Jeannet. 1991. Application of DR oligotyping to 110 kidney transplant patients with doubtful serological typing. Transplantation (Baltimore). 51:110-114.

26. Tiercy, J. M., C. Morel, A. C. Freidel, F. Zwahlen, L. Gebuhrer, H. Betuel, M. Jeannet, and B. Mach. 1991. Selection of unrelated donors for bone marrow transplantation is improved by HLA class II genotyping with oligonucleotide hybridization. Proc. Natl. Acad. Sci. USA. 88:7121-7125.

27. Tiwari, J. L., and P. I. Terasaki, editors. 1985. HLA and Disease Association. The Data and Statistical Analysis. Springer Verlag, New-York, 18-27.

28. Tait, B. D., G. Mraz, and L. C. Harrison. 1988. Association of HLADQw3 ( TA10-) with type I diabetes occurs with DR3/4 but not DR1 / 4 patients. Diabetes. 37:926-929.

29. Rowe, J. R., E. M. Mickelson, J. A. Hansen, M. J. MacDonald, C. T. Allen, K. H. Gabbay, E. J. Yunis, and M. J. Sheehy. 1988. T cell-defined DR4 subtypes as markers for type I diabetes. Hum. Immunol. 22:51-60.

30. Papoz, L., F. Vauzelle, P. Vexiau, and G. Cathelineau. 1988. Pattern of treatment among diabetic patients in France. Diabetes Care. 11:586-591.

31. Cohen, D., O. Cohen, A. Marcadet, C. Massart, M. Lathrop, I. Deschamps, J. Hors, E. Schuller, and J. Dausset. 1984. Class II HLA-DC $\beta$-chain DNA restriction fragments differentiate among HLA-DR2 individuals in insulindependent diabetes and multiple sclerosis. Proc. Natl. Acad. Sci. USA. 81:17741778.

32. Segall, M., H. Noreen, L. Schulender, M. Swenson, J. Bardosa, and F. H. Bach. 1986. DR2 + haplotypes in insulin-dependent diabetes: analysis of DNA restriction fragment length polymorphisms. Human. Immunol. 17:61-68.

33. Erlich, H. A., R. L. Griffith, T. L. Bugawan, R. Ziegler, C. Alper, and G. Eisenbarth. 1991. Implication of specific DQB1 alleles in genetic susceptibility and resistance by identification of IDDM siblings with novel HLA-DQB1 allele and unusual DR2 and DR1 haplotypes. Diabetes. 40:478-481.

34. Cohen-Haguenauer, O., E. Robbins, C. Massart, M. Busson, I. Deschamps, J. Hors, J. M. Lalouel, J. Dausset, and D. Cohen. 1985. A systematic study of HLA class II- $\beta$ DNA restriction fragments in insulin-dependent diabetes mellitus. Proc. Natl. Acad. Sci. USA. 82:3335-3339.

35. Khalil, I., L. d'Auriol, M. Gobet, L. Morin, V. Lepage, I. Deschamps, M. S. Park, L. Degos, F. Galibert, and J. Hors. 1990. A combination of HLA$\mathrm{DQ} \beta$ Asp57-negative and HLA-DQ $\alpha$ Arg52 confers susceptibility to insulin-dependent diabetes mellitus. J. Clin. Invest. 85:1315-1319.

36. Groop, L. C., G. F. Bottazzo, and D. Doniach. 1986. Islet cell antibodies identify latent type I diabetes in patients aged 35-75 years at diagnosis. Diabetes. 35:237-241.

37. Fajans, S. S., and J. W. Conn. 1965. Prediabetes, subclinical diabetes, and latent clinical diabetes: interpretation, diagnosis and treatment. In On the Nature and Treatment of Diabetes. D. S. Leibel, and G. S. Wrenshall, editors. Excerpta Med, Amsterdam. 641-656.

38. Winter, W. E., N. K. MacLaren, J. W. Riley, D. W. Clarke, M. S. Kappy, and R. P. Spillar. 1987. Maturity-onset diabetes of youth in black Americans. $N$. Engl. J. Med. 316:285-291.

39. Wolf, E., K. M. Spencer, and A. G. Cudworth. 1983. The genetic suscepti- bility to type 1 (insulin-dependent) diabetes: analysis of the HLA-DR association. Diabetologia. 24:224-230.

40. Knip, M., J. Ilonen, A. Mustonen, and H. K. Åkerblom. 1986. Evidence of an accelerated B-cell destruction in HLA-Dw3/Dw4 heterozygous children with type 1 (insulin-dependent) diabetes. Diabetologia. 29:347-351.

41. Nepom, B. S., J. Palmer, S. J. Kim, J. A. Hansen, S. L. Holbeck, and G. T. Nepom. 1986. Specific genomic markers of the HLA-DQ subregion discriminate between DR4+ insulin-dependent diabetes mellitus and DR4+ seropositive juvenile rheumatoid arthritis. J. Exp. Med. 164:345-350.

42. Scharf, S. J., A. Friedmann, C. Brautbar, F. Szafer, L. Steinman, G. Horn, U. Gyllensten, and H. Erlich. 1988. HLA class II allelic variation and susceptibility to pemphigus vulgaris. Proc. Natl. Acad. Sci. USA. 85:3504-3508.

43. Nepom, G. T., and D. M. Robinson. 1990. HLA-DQ and diabetes mellitus: genetic and structural paradigm for models of disease susceptibility. In The Molecular Biology of Auto-immune Disease. A. Demaine, editor. Springer Verlag, Berlin. 251-262.

44. Kwok, W. W., D. Schwarz, B. Nepom, P. Thurtle, R. Hock, and G. T. Nepom. 1988. HLA-DQ molecules form $\alpha-\beta$ heterodimers of mixed allotype. $J$ Immunol. 141:3123-3127.

45. Kwok, W. W., E. Mickelson, S. Masewicz, E. C. B. Milner, J. Hansen, and G. T. Nepom. 1990. Polymorphic DQ $\alpha$ and DQ $\beta$ interactions dictate HLA class II determinants of allo-recognition. J. Exp. Med. 171:85-95.

46. Charron, D. 1990. Molecular basis of human leukocyte antigen class II disease association. Adv. Immunol. 48:107-159.

47. Aparicio, J. M., A. Wakisaka, A. Takada, N. Matsuura, and M. Aizawa. 1988. HLA-DQ system and insulin-dependent diabetes mellitus in Japanese: does it contribute to the development of IDDM as it does in Caucasians? Immuno genetics. 28:240-246.

48. Todd, J. A., C. Mijovic, J. Fletcher, D. Jenkins, A. L. Bradwell, and A. H Barnett. 1989. Identification of susceptibility loci for insulin dependent diabetes mellitus by trans-racial gene mapping. Nature (Lond.). 338:587-589.

49. Karjalainen, J., P. Salmela, J. Ilonen, H. M. Surcel, and M. Knip. 1989. A comparison of childhood and adult type I diabetes mellitus. N. Engl. J. Med. 320:881-886.

50. Foulis, A. K., N. D. Francis, M. A. Fugquharson, and A. Boylston. 1988. Massive synchronous B-cell necrosis causing Type 1 (insulin-dependent) diabetes. A unique histopathological case report. Diabetologia. 31:46-50.

51. Dawkins, R. L., E. Martin, G. Saueracker, P. H. Kay, A. Leaver, and F. T. Christiansen. 1990. Supratypes and ancestral haplotypes in IDDM: potential importance of central non-H1A MHC genes. J. Autoimmun. 3(Suppl.):63-68.

52. Nepom, G. T., and H. Erlich. 1991. MHC class II molecules and autoimmunity. Annu. Rev. Immunol. 9:493-525.

53. Andersen, L. C., J. S. Beaty, J. W. Nettles, C. E. Seyfried, G. T. Nepom and B. S. Nepom. 1991. Allelic polymorphism in transcriptional regulatory regions of HLA-DQB genes. J. Exp. Med. 173:181-192.

54. Garchon, H. J., P. Bedossa, L. Eloy, and J. F. Bach. 1991. Identification and mapping to chromosome 1 of a susceptibility locus for periinsulitis in nonobese diabetic mice. Nature (Lond.). 353:260-262.

55. Cornall, R. J., J. B. Prins, J. A. Todd, A. Pressey, N. H. De Carato, L. S. Wicker, and L. B. Peterson. 1991. Type 1 diabetes in mice is linked to the interleukin-1 receptor and Lsh/Ity/Bcg genes on chromosome 1. Nature (Lond.). 353:262-264. 